\title{
Kemampuan Bernalar Ilmiah Mahasiswa Pada Mata Kuliah Kimia Teknik
}

\author{
Maya Erliza Anggraeni \\ Program Studi Pendidikan Kimia, FKIP, Universitas Palangka Raya, Indonesia
}

\begin{abstract}
Abstrak: Kemampuan bernalar ilmiah (scientific reasoning) diperlukan dalam memahami sains termasuk kimia. Pola-pola penalaran ilmiah memungkinkan mahasiswa menganalisis fakta atau informasi secara logis dan sistematis. Mahasiswa dengan kemampuan bernalar ilmiah yang baik diharapkan dapat mengkonstruk konsep dengan lebih baik. Penelitian ini bertujuan untuk mendeskripsikan kemampuan bernalar ilmiah mahasiswa Pendidikan Teknik Mesin pada mata kuliah Kimia Teknik. Subjek penelitian berjumlah 65 orang. Kemampuan bernalar ilmiah mahasiswa diukur Classroom Test of Scientific Reasoning (CTSR). Berdasarkan skor tes CTSR ini maka tingkat perkembangan mahasiswa dapat dikategorikan ke dalam empat tingkat perkembangan yaitu tingkat concrete, low formal, upper formal dan post formal. Hasil penelitian menunjukkan, sebanyak $89 \%$ mahasiswa masih berada pada tingkat bernalar concrete dan hanya $11 \%$ yang mencapai tingkat bernalar low formal. Hal ini menunjukkan tingkat kemampuan bernalar ilmiah mahasiswa masih rendah dan ada keterlambatan perkembangan kemampuan bernalar. Jenis penalaran paling rendah yaitu pola penalaran probabilitas dan pola penalaran konservasi merupakan penalaran yang paling dikuasai oleh mahasiswa.
\end{abstract}

\section{Kata kunci: kemampuan bernalar ilmiah, kimia teknik}

\section{Pendahuluan}

Kimia teknik merupakan salah satu mata kuliah wajib pada Program Studi Pendidikan Teknik Mesin Universitas Palangka Raya. Materi yang dipelajari pada mata kuliah ini adalah pengetahuan dasar kimia yang meliputi energi dan materi, stoikiometri, teori gas ideal, reaksi redoks, kimia bahan bakar, air untuk industri, minyak pelumas, elektrolisis, unsur logam dan paduannya serta limbah industri. Mata kuliah ini bertujuan agar mahasiswa dapat memiliki kemampuan tentang konsep-konsep dasar kimia teknik dan sifat-sifat kimia beserta pengaruh-pengaruh kimia dalam pemakaian di bidang teknik mesin. Untuk mencapai tujuan ini diperlukan kemampuan pemahaman konten dan juga kemampuan penalaran yang baik. Kemampuan-kemampuan tersebut berhubungan dengan kemampuan kognitif seperti berpikir kritis dan penalaran. Kemampuan penalaran yang digunakan dalam bidang sains disebut kemampuan bernalar ilmiah (Scientific Reasoning).

Kemampuan bernalar ilmiah adalah (KBI) keterampilan kognitif yang diperlukan untuk memahami dan mengevaluasi informasi ilmiah, yang melibatkan pemahaman dan evaluasi secara teoritis, statistik, dan hipotesis kausal (Bao et al., 2009). KBI memungkinkan siswa untuk menganalisis fakta atau informasi secara logis dan sistematis (Lawson, 2004; Schen, 2007). Siswa yang memiliki KBI yang tinggi cenderung lebih mudah memproses dan mengkonstruksi informasi dengan benar 
sehingga memungkinkan siswa memahami konsep dengan lebih baik (Cracolice $e t$ al., 2008; Oloyede, 2012).

KBI meliputi kemampuan berpikir yang terlibat dalam tahap penyelidikan ilmiah, eksperimen, evaluasi fakta-fakta, inferensi dan argumentasi (Zimmerman, 2005). KBI sangat diperlukan dalam memahami sains termasuk kimia sebab kimia dipahami dan kembangkan melalui penyelidikan ilmiah. KBI terdiri dari keseluruhan pola penalaran yang dikarakterisasikan sebagai hipotetik-deduktif dan beberapa subpola, yang merupakan bagian skema operasional formal seperti penalaran proporsional, kombinasi dan korelasi (Lawson, 2004:308). Menurut Lawson (2004) dan Colleta (2013) untuk berpikir ilmiah harus menggunakan penalaran formal atau penalaran di atas tingkatan formal. Oleh karena itu, untuk memahami sains dengan baik membutuhkan setidaknya penalaran pada tahap operasi formal.

Menurut teori Piaget setiap individu mengalami tingkat-tingkat perkembangan kognitif, yaitu: (1) Tingkat berpikir sensorimotor; usia anak diperkirakan 0-2 tahun, (2) Tingkat berpikir praoperasional; usia anak diperkirakan 2-7 tahun, (3) Tingkat berpikir operasi konkret; usia anak diperkirakan 7-11 tahun, dan (4) Tingkat berpikir operasi formal; usia anak diperkirakan 11 tahun ke atas. Tahap-tahap perkembangan kognitif tersebut bersifat tetap, yang berarti dalam proses perkembangan menuju ke tahap yang lebih tinggi individu tidak dapat meloncati tahap perkembangan sebelumnya (Sund dan Trowbridge, 1973). Berdasarkan teori Piaget ini, maka mahasiswa seharusnya sudah berada pada tingkat kemampuan penalaran formal.

Tingkat penalaran formal atau KBI diukur berdasarkan kemampuan memahami masalah yang berhubungan dengan konservasi materi dan volume, melakukan penalaran proporsional, memahami masalah yang berhubungan dengan kontrol variabel, menyelesaikan penalaran yang berhubungan dengan probabilitas, melakukan penalaran korelasi, dan penalaran hipotetik-deduktif. Berikut penjelasan pola-pola penalaran dalam KBI.

\section{Kemampuan Konservasi Massa Dan Volume (Conservation of Matter and Volume)}

Persamaan reaksi kimia adalah salah satu konsep yang memerlukan kemampuan konservasi. Pada reaksi kimia berlaku hukum kekekalan massa, yaitu massa sebelum dan sesudah reaksi adalah sama. Agar memenuhi hukum kekekalan massa maka dalam menuliskan persamaan reaksi, jumlah setiap atom sesudah reaksi harus sama dengan jumlah atom sebelum reaksi.

\section{Penalaran Proporsional (Proportional Reasoning)}

Penalaran proporsional penting dalam aspek kuantitatif kimia, terutama untuk memahami derivasi dan penggunaan sejumlah besar hubungan fungsional dalam kimia, seperti pengembangan dan interpretasi data tabulasi dan grafik. 
(Wiji et al., 2014). Penalaran proporsional sangat dibutuhkan dalam memahami kimia sebab konsep-konsep kimia seringkali dideskripsikan dalam bentuk permasalahan kuantitatif (Herron, 1996). Rumus molekul, persamaan reaksi dan stoikiometri merupakan bentuk hubungan kuantitatif.

\section{Kontrol Variabel (Control of Variables)}

Pengontrolan variabel penting dalam perencanaan, pelaksanaan dan interpretasi (Wiji et al., 2014). Pengontrolan variabel merupakan proses pengontrolan variabel-variabel independen yang mempengaruhi keberlanjutan kondisi selama pengujian hipotesis (Piraksa et al., 2014).

\section{Penalaran Probabilitas (Probability Reasoning)}

Interpretasi data dari temuan, pengamatan, atau percobaan sering membutuhkan penalaran probabilistik (Wiji et al., 2014). Penalaran probabilitas memungkinkan individu memprediksikan kemungkinan yang muncul dari proses tertentu yang menghasilkan hasil tertentu ketika diulangi pada kondisi yang sama (Piraksa et al., 2014).

\section{Penalaran Korelasional (Correlation Reasoning)}

Penalaran korelasional didefinisikan sebagai pola pikir individu gunakan untuk menentukan kekuatan hubungan timbal balik antar variabel (Lawson, 2004). Penalaran korelasional berperan dalam perumusan hipotesis dan interpretasi data yang perlu mempertimbangkan hubungan antar variabel (Wiji et al., 2014).

\section{Penalaran Hipotetik-Deduktif (Hypothetico-Deductive Reasoning)}

Penalaran hipotetik-deduktif memungkinkan individu yang berada pada tahap operasi formal dapat menyusun hipotesis (dugaan terbaik) tentang cara untuk memecahkan masalah dan menarik kesimpulan secara sistematis (Mutammam \& Budiarto, 2013).

\section{Metode Penelitian}

Penelitian ini menggunakan desain deskriptif untuk mendeskripsikan tingkat kemampuan bernalar mahasiswa. Subjek penelitian ini adalah mahasiswa Pendidikan Teknik Mesin pada mata kuliah Kimia Teknik yang berjumlah 65 orang. Instrumen yang digunakan adalah The Classroom Test Of Scientific Reasoning (CTSR) edisi revisi tahun 2000 yang dikembangkan oleh Lawson dan telah diterjemahkan ke dalam Bahasa Indonesia. CTSR terdiri dari 24 butir soal pilihan ganda. Instrumen ini sudah umum dan efektif digunakan untuk mengukur KBI siswa dan mahasiswa biologi (Lawson et al., 2007), fisika (Bao et al., 2009), kimia (Oloyede, 2012) dan sains (Liao \& She, 2009). Berikut aspek yang diukur dalam CTSR. 
Tabel 1. Kisi-kisi Tes Kemampuan Berpikir Ilmiah

\begin{tabular}{|c|l|c|}
\hline No & Aspek Berpikir yang Diukur & Nomor Soal \\
\hline 1 & Konservasi & $1,2,3,4$ \\
\hline 2 & Berpikir proporsional & $5,6,7,8$ \\
\hline 3 & Identifikasi dan kontrol variabel & 9,10 \\
\hline 4 & Identifikasi dan kontrol variabel serta berpikir probabilitas & $11,12,13,14$ \\
\hline 5 & Berpikir probabilitas & $15,16,17,18$ \\
\hline 6 & $\begin{array}{l}\text { Berpikir korelasional (mencakup juga berpikir proporsional } \\
\text { dan probabilitas }\end{array}$ & 19,20 \\
\hline 7 & Berpikir hipotetik-deduktif & $21,22,23,24$ \\
\hline
\end{tabular}

Teknik penskoran pada tes KBI adalah dengan memberikan skor 1 pada setiap item soal yang dijawab dengan benar dan skor 0 pada setiap item soal yang dijawab salah. Dengan demikian, skor tertinggi adalah 24 dan terendah adalah 0. Tingkat KBI siswa ditentukan berdasarkan kriteria yang disajian pada tabel 2 berikut. Hasil uji reliabilitas tes KBI menunjukkan koefisien $\alpha$-cronbach antara 0,71-0,78 (Asnawi, 2015; Lawson, 2004) yang menggambarkan bahwa reliabilitas temasuk kategori tinggi.

Tabel 2. Kriteria Tingkat KBI Mahasiswa Berdasarkan Skor CTSR

\begin{tabular}{|c|c|c|}
\hline No & Skor CTSR & Tingkat KBI \\
\hline 1 & $0-9$ & Concrete \\
\hline 2 & $10-14$ & Low formal \\
\hline 3 & $15-19$ & Upper formal \\
\hline 4 & $20-24$ & Post formal \\
\hline
\end{tabular}

\section{Hasil Penelitian Dan Pembahasan}

Berdasarkan kriteria tingkat KBI yang diusulkan oleh Lawson, tingkat perkembangan mahasiswa digolongkan menjadi dua yaitu tingkat concrete dan low formal. Belum ada mahasiswa yang telah mencapai tingkat Upper formal dan Post formal. Tingkat perkembangan KBI mahasiwa disajikan pada tabel 3, sedangkan grafik skor total KBI berdasarkan jenis penalaran disajikan pada gambar 1 berikut.

Tabel 3. Tingkat Perkembangan Kemampuan Bernalar Mahasiswa

\begin{tabular}{|l|l|l|}
\hline Tingkat KBI & Jumlah & Persentase \\
\hline Concrete & 58 & $89 \%$ \\
\hline Low formal & 7 & $11 \%$ \\
\hline Upper formal & 0 & $0 \%$ \\
\hline Post formal & 0 & $0 \%$ \\
\hline
\end{tabular}


Berdasarkan tabel 3, tingkat kemampuan bernalar ilmiah mahasiswa masih rendah. Usia mahasiswa semester satu pada mata kuliah Kimia Teknik berkisar antara 18-21 tahun. Berdasarkan tahap perkembangan kognitif Piaget, pada usia ini seharusnya mahasiswa sudah berada pada tahap kemampuan berpikir formal. Menurut Lawson (2004) mahasiswa yang sudah berada di atas usia 18 tahun bahkan telah melampaui tahap perkembangan operasi formal. Mahasiswa pada semester satu seharusnya sudah berada pada tahap perkembangan post formal. Namun penelitian menunjukkan adanya keterlambatan perkembangan kemampuan bernalar pada mahasiswa. Temuan ini sejalan dengan beberapa penelitian sebelumnya (Valanides, 1997; Lawson, 2004 dan Asnawi, 2015).

Menurut Lawson, et al (2000), individu yang memiliki level KBI post formal akan mampu memahami konsep yang bersifat deskriptif (dapat diamati), teoritik, dan hipotetik. Individu yang berada pada level upper formal dan low formal mampu memahami konsep yang bersifat deskriptif dan hipotetik sedangkan individu yang berada pada level concret hanya mampu memahami konsep deskriptif. Berdasarkan karakteristik materi kimia teknik ini maka mahasiswa yang masih berada pada tahap berpikir concrete akan mengalami kesulitan memahami mata kuliah kimia yang sarat akan konsep abstrak, teoritik, dan hipotetik serta banyak menerapkan konsep dalam hubungan kuantitatif.

Mahasiswa yang memiliki tingkat berpikir concrete membutuhkan referensi, objek, dan sifat deskriptif yang familiar. Pada tingkat ini, penalaran mahasiswa diawali dengan pengamatan. Mahasiswa yang berada pada tingkat penalaran transisi berada pemikiran konkret atau hanya mampu melakukan penalaran formal secara parsial (Tajudin, 2015). Mahasiswa yang berada pada level upper formal dan low formal diduga masih berada pada tahap transisi sehingga memungkinkan untuk mengalami kesulitan memahami konsep abstrak. Dengan demikian, rendahnya tingkat perkembangan kemampuan bernalar mahasiswa menyebabkan kesulitan memahami mata kuliah Kimia Teknik.

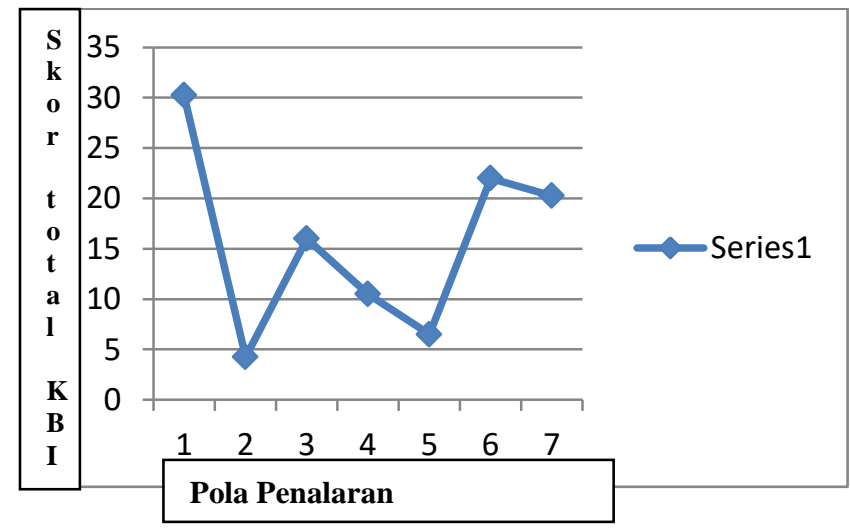

Gambar 1. Grafik Skor Total KBI Berdasarkan Jenis Penalaran 
Gambar 1 menunjukkan penalaran paling rendah yaitu pola penalaran probabilitas sedangkan pola penalaran konservasi merupakan penalaran yang paling dikuasai oleh mahasiswa. Penalaran konservasi yang baik memungkinkan mahasiswa memahami dan menyetarakan persamaan reaksi kimia. Hal ini ditunjukkan dalam proses pembelajaran, mahasiswa tidak mengalami kesulitan berarti ketika diminta menyetarakan persamaan reaksi. Mahasiswa telah memahami hukum dasar kimia yaitu massa sebelum dan setelah reaksi adalah sama sehingga jumlah atom sebelum dan setelah reaksi juga harus sama.

Penalaran probabilitas membantu mahasiswa dalam memprediksikan kemungkinan suatu proses atau data ketika diulangi pada kondisi yang sama. Jenis penalaran ini membantu mahasiswa dalam memahami konsep yang memerlukan pemahaman konsep yang berupa interpretasi data contohnya pada Teori Gas. Penalaran probabilitas yang lemah menyebabkan mahasiswa mengalami kesulitan menggeneralisasikan konsep berdasarkan data atau grafik. Hal ini terjadi dalam proses pmbelajaran materi Hukum Gas Ideal, sebagian mahasiswa tidak dapat menginterpretasikan hubungan antara tekanan, volume, suhu dan jumlah molekul berdasarkan data atau grafik.

Pola-pola penalaran kemampuan bernalar memungkinkan mahasiswa dapat memahami kimia dengan lebih baik. Oleh karena itu proses pembelajaran seharusnya melibatkan perkembangan skemata formal (Adey \& Shayer, 1990). Hubungan antara metode pembelajaran dan pengembangan pola penalaran ilmiah telah banyak dipelajari dan menunjukkan bahwa pembelajaran sains berbasis penyelidikan (inquiry) dapat mengembangkan kemampuan penalaran ilmiah (Bao, et al., 2009).

Pentingnya mengembangkan kemampuan bernalar karena memiliki dampak jangka panjang pada penguasaan konsep dan kemampuan memecahkan masalah (Colleta \& Philips, 2005). Kemampuan penalaran ilmiah dan kebiasaan bernalar merupakan inti dari literasi ilmiah, yang melibatkan: (1) kemampuan dan kebiasaan bernalar untuk mengkonstruksi pemahaman, (2) memahami konsep sains secara utuh, dan (3) kemampuan berkomunikasi untuk menginformasikan dan meyakinkan orang lain untuk mengambil tindakan terkait dengan konsep dan teori tersebut.

\section{Kesimpulan}

Berdasarkan hasil analisis data, maka dapat disimpulkan beberapa hal sebagai berikut. (1) tingkat kemampuan bernalar ilmiah mahasiswa masih rendah dan ada keterlambatan perkembangan kemampuan bernalar. (2) pola penalaran konservasi merupakan penalaran yang paling dikuasai oleh mahasiswa. Penalaran paling rendah yaitu pola penalaran probabilitas. 


\section{Implikasi Hasil Penelitian}

Kemampuan bernalar ilmiah mahasiswa masih rendah menyebabkan kesulitan memahami konsep dasar kimia seperti stoikiometri dan hukum gas. Oleh karena itu, perlu dilakukan kajian mendalam tentang bahan ajar dan desain pembelajaran yang dapat mengembangkan kemampuan pemahaman konten dan juga kemampuan bernalar. Pembelajaran yang dapat mengembangkan skemata formal seperti konservasi, kontrol variabel, penalaran korelasional seperti pada scientific approach dapat dipertimbangkan. Kemampuan bernalar tidak hanya memudahkan mahasiswa memahami konsep tetapi juga menyelesaikan masalah dalam kehidupan sehari-hari.

\section{Daftar Pustaka}

Adey, P., \& Shayer, M. 1990. Accelerating the development of formal thinking in middleand high school students. Journal of Research in Science Teaching, 27(3), $267-285$.

Asnawi, R. 2015. Miskonsepsi pada Materi Elektrokimia Ditinjau dari Kemampuan Berpikir Ilmiah Siswa. Tesis tidak diterbitkan. Malang: Pascasarjana Universitas Negeri Malang.

Bao, L., T. Cai, K. Koenig, K. Fang, J. Han, J. Wang, Q. Liu. 2009. Learning and scientific reasoning. Science, 323 (5914): 586-587.

Coletta, V. P., \& Phillips, J. A. 2005. Interpreting FCI Scores: Normalized Gain, Preinstruction Scores, And Scientific Reasoning Ability. American Journal of Physics, 73(12), 1172-1182.

Cracolice, Mark S.; Deming, John C.; Ehlert, Brian. 2008. Concept Learning versus Problem Solving: A Cognitive Difference. Journal of Chemical Education, 85(6): 873-879.

Lawson, A.E. 2000. The Generality Of Hypothetico-Deductive Reasoning: Making Scientific Reasoning Explicit. The American Biology Teacher, 62(7):482-495.

Lawson, A. E. 2004. The Nature And Development Of Scientific Reasoning: A Synthetic View. International Journal of Science and Mathematics Education 2(3): 307-338.

Lawson, A. E., Banks, D. L., \& Logvin, M. 2007. Self-Efficacy, Reasoning Ability, And Achievement In College Biology. Journal of Research in Science Teaching, 44(5), 706-724.

Liao, Y. W. \& She, H. C. 2009. Enhancing Eight Grade Students' Scientific Conceptual Change and Scientific Reasoning through a Web-based Learning Program. Educational Technology \& Society 12(4): 228-240.

Mutammam, M. B dan Budiarto, M. T. 2013. Pemetaan Perkembangan Kognitif Piaget Siswa Sma Menggunakan Tes Operasi Logis (TOL) Piaget Ditinjau Dari Perbedaan Jenis Kelamin. E-journal Unesa, 2(2).

Oloyede, O. I. 2012. The Relationship between Acquisition of Science Process Skills, Formal Reasoning Ability and Chemistry Achievement. International Journal of African \& African- American Studies, 8(1): 1-4. 
Piraksa, C., Srisawasdi, N. \& Koul, R. 2014. Effect of Gender on Students' Scientific Reasoning Ability : A Case Study in Thailand. Procedia - Social and Behavioral Sciences 116: 486 - 491.

Schen, M.S. 2007. Scientific Reasoning Skills Development In The Introductory Biology Courses For Undergraduates. Unpublished Doctoral Dissertation, The Ohio State University.

Sund \& Trowbridge. 1973. Teaching Science by Inquiry in the Secondary School. Columbus: Charles E. Merill Publishing Company.

Tajudin, N.M \& Chinnappan, M. 2015. In M. Marshman, V. Geiger, \& A. Bennison (Eds.). Mathematics education in the margins (Proceedings of the 38th annual conference of the Mathematics Education Research Group of Australasia), pp. 603-610. Sunshine Coast: MERGA.

Wiji., Liliasari., Sopandi, W., Martoprawiro, M. A. K.. 2014. Kemampuan Berpikir Logis dan Model Mental Kimia Sekolah Mahasiswa Calon Guru. Cakrawala Pendidikan 33(1): 147-156.

Zimmerman, C. 2005. The development of scientific reasoning: What psychologists contribute to an understanding of elementary science learning. Paper commissioned by the National Academies of Science (National Research Council's Board of Science Education, Consensus Study on Learning Science, Kindergarten through Eighth Grade). 